\title{
Prostate cancer risk and nonsteroidal antiinflammatory drug use in the Finnish prostate cancer screening trial
}

\author{
T Veitonmäki ${ }^{*, 1,2,8}$, T J Murtola ${ }^{1,3,8}$, L Määttänen ${ }^{4}, \mathrm{~K} \mathrm{Taari}^{5,6}, \mathrm{U}-\mathrm{H}$ Stenman ${ }^{7}$, T L J Tammela ${ }^{1,3}$ and A Auvinen ${ }^{2}$ \\ ${ }^{1}$ Department of Urology, Tampere University Hospital, Teiskontie 35, 33521 Tampere, Finland; ${ }^{2}$ School of Health Sciences, \\ University of Tampere, Medisiinarinkatu 3, 33520 Tampere, Finland; ${ }^{3}$ School of Medicine, University of Tampere, Lääkärinkatu 1, \\ 33520 Tampere, Finland; ${ }^{4}$ Finnish Cancer Registry, Pieni Roobertinkatu 9, 00130 Helsinki, Finland; ${ }^{5}$ Department of Urology, \\ Helsinki University Hospital, Sairaalakatu 1, 01400 Vantaa, Finland; ${ }^{6}$ School of Medicine, University of Helsinki, Tukholmankatu 8 B, \\ 00014 Helsinki, Finland and 'Department of Clinical Chemistry, Helsinki University Hospital, Haartmaninkatu 4, 00290 Helsinki, \\ Finland
}

Background: The association between nonsteroidal antiinflammatory drugs (NSAIDs) and prostate cancer risk remains controversial. We examined the risk among NSAID users in 78615 men in the Finnish Prostate Cancer Screening Trial.

Methods: We obtained information on NSAID prescription usage from Finnish nationwide prescription database and on over-thecounter use by a questionnaire. Prostate cancer cases were identified from the Finnish Cancer Registry.

Results: Prostate cancer risk was elevated among current NSAID prescription users irrespective of screening (hazard ratio $(H R)=1.45$, confidence interval $(95 \% \mathrm{Cl})=1.33-1.59$ and $\mathrm{HR}=1.71,95 \% \mathrm{Cl}=1.58-1.86$ in the screening and control arm, respectively), but not for previous use of NSAIDs. The risk increase was similar among coxib and acetaminophen current users, and stronger for metastatic prostate cancer $(\mathrm{HR}=2.41,95 \% \mathrm{Cl}=1.59-3.67$ and $\mathrm{HR}=3.44,95 \% \mathrm{Cl}=2.60-4.55$ in the screening and control arm, respectively). Previous use of NSAIDs, aspirin use and over-the-counter NSAID usage were not associated with prostate cancer

Conclusions: Differing association for current and previous use suggests that the risk increase is unlikely to be directly caused by the medication, but may be due to the conditions indicating NSAID prescription usage, such as symptoms of undiagnosed prostate cancer. To reduce inconsistency between the study outcomes, future epidemiological studies on NSAID use and prostate cancer risk should assess the indications for NSAID usage.

Prostate cancer is the most common malignancy and the second most common cause of cancer death among Western men (Ferlay et al, 2010; Siegel et al, 2011). Age, AfricanAmerican ethnicity and family history of prostate cancer are the established risk factors (Steinberg et al, 1990; Crawford, 2009), while other aetiological factors remain debatable. The pathogenesis of prostate cancer involves environmental factors as the risk increases with the adoption of a 'westernised' lifestyle. One such potential environmental factor might be the development of chronic inflammation in the prostate (De Marzo et al, 2007). Several lines of research have pointed to a role of inflammation in prostatic carcinogenesis and tumour progression (De Nunzio et al, 2011; Sfanos and De Marzo, 2012). Chronic inflammatory conditions are associated with many neoplasms such as colon, hepatic and bladder carcinoma (Coussens and Werb, 2002).

\footnotetext{
*Correspondence: Dr T Veitonmäki; E-mail: thea.veitonmaki@uta.fi

${ }^{8}$ These authors contributed equally to this work.
}

Received 16 March 2014; revised 8 June 2014; accepted 15 June 2014; published online 10 July 2014 
COX-2 is an inducible enzyme that facilitates inflammation by catalysing the conversion of arachidonic acid to prostaglandins (Hussain et al, 2003). COX-2 is overexpressed in prostate carcinoma (Gupta et al, 2000) and might have an important role in the proliferation of cancer cells (Yoshimura et al, 2000). COX-2 overexpression correlates with prostate cancer stage and mortality (Richardsen et al, 2010; Shao et al, 2012). Nonsteroidal antiinflammatory drugs (NSAIDs), which inhibit the COX-2 pathway, could also reduce prostate cancer risk. NSAIDs might work also through a COX-2- independent pathway suppressing oncogenic $\beta$-catenin signalling, inhibiting angiogenesis, promoting tumour cell invasion and inducing apoptosis (Gurpinar et al, 2014). Aspirin and NSAID use has been associated with a decreased risk of several other cancers such as colorectal, oesophageal, gastric, breast and bladder cancer (Khuder and Mutgi, 2001; Corley et al, 2003; Rostom et al, 2007; Cuzick et al, 2009; Tian et al, 2010; Daugherty et al, 2011).

The association between NSAID use and prostate cancer risk remains controversial. Epidemiological evidence suggests that prostate cancer risk is reduced by $10 \%$ in regular aspirin users (Bosetti et al, 2012; Veitonmäki et al, 2013). Also other NSAIDs may have a protective association against prostate cancer (Mahmud et al, 2010). However, a clear relationship between risk reduction and frequency, dose or duration of use has not been shown (Mahmud et al, 2010; Bosetti et al, 2012; Veitonmäki et al, 2013). In our previous study, we examined the prostate cancer risk for prescription NSAID users in a nationwide population-based case-control study with a large and partly overlapping study population, but without information on screening (Veitonmäki et al, 2013). Compared with the nonusers, any NSAID use was associated with an elevated overall prostate cancer risk.

In this study, we examined the risk between NSAID and acetaminophen use and prostate cancer incidence in men attending the Finnish Prostate Cancer Screening Trial during 1996-2009.

\section{MATERIALS AND METHODS}

The Finnish Prostate Cancer Screening Trial is the largest component of the European Randomized Study of Prostate Cancer Screening (de Koning et al, 2002). In 1996-1999, all men aged 55, 59,63 or 67 years and residing in the metropolitan areas of Helsinki and Tampere (a total of 80484 men) were annually identified from the population register of Finland. After exclusion of prevalent prostate cancer cases, 80144 men were randomly assigned either for PSA-based screening (31 866 men, the screening arm) or to be followed through national registries (48 $278 \mathrm{men}$, the control arm). Men in the screening arm were recruited with mailed invitations to undergo a prostate-specific antigen (PSA) screening test at four-year intervals until the age of 71 years. Men with serum PSA greater than or equal to $4 \mathrm{ng} \mathrm{ml}^{-1}$ were referred to a urological clinic for diagnostic examinations, including digital rectal examination (DRE), transrectal ultrasound and prostate biopsy. Men with a PSA level of 3.0-3.9 $\mathrm{ng} \mathrm{ml}^{-1}$ were referred to an additional test, which was DRE during 1996-1998 and since 1999 a free/total PSA (F/T PSA) ratio with a cutoff point of $16 \%$. Men with any of the above findings were considered screenpositive.

The first screening round was carried out during 1996-1999, the second 2000-2003 and the third in 2004-2007. Men who had emigrated from the study area or were diagnosed with prostate cancer were not re-invited. Information on vital status and emigration was obtained from the Population Register Centre. For information on prevalent prostate cancer cases at randomisation, cases diagnosed in the control arm and between the screening rounds, the study cohort was annually linked to the Finnish Cancer
Registry (Kilpeläinen et al, 2013). Information on cancer incidence, medication use and vital status was available until the end of 2009.

Finnish Cancer Registry is a population-based, nationwide register that collects data through mandatory notifications of all cancer diagnoses made by the Finnish health care units. It covers more than 99\% of all cancer cases in Finland (Teppo et al, 1994). The register information includes the primary site of cancer, histology, date and method of diagnosis. Serum PSA values and tumour Gleason scores were obtained from the trial database.

Information on physician-prescribed antiinflammatory medication purchases during 1995-2009 was obtained from the comprehensive nationwide prescription database of the Social Insurance Institution (SII) of Finland. The SII is a governmental agency operating under the ministry of health and provides reimbursements for the cost of medicines prescribed by a physician with the exception of hospital inpatients. The reimbursement is available for all Finnish residents for each purchase of a physicianprescribed drug that has been approved as reimbursable by the SII. The prescription database records the amount, dose and date for each reimbursed purchase. Most prescription drugs in clinical use in Finland have been approved as reimbursable, thus recorded by the database. Purchases of prescription-free drugs are not recorded (Martikainen and Rajaniemi, 2002). The prescription NSAIDs available in Finland are shown in Supplementary Table 1. The medication data was available for 78615 men $(98.1 \%$ of the screening trial population). The study flow chart is shown in Figure 1.

To obtain information on over-the-counter usage, the participants of the third screening (years 2004-2007) round were sent a questionnaire on over-the-counter NSAID use with $92.6 \%$ response rate of the screened men. The survey included questions about frequency, dose and duration of over-the-counter usage during this time since 1990 to the present. The survey included questions separately for ibuprofen, dexibuprofen, ketoprofen, aspirin and acetaminophen use.

Information on the comorbidities during hospitalisations in the study population was gained from the Care Registers for Social Welfare and Health Care (HILMO) by the national institutes for Health and Welfare. The registry gathers the information of any hospitalisation in Finnish health care units and information of the diagnoses are registered as ICD-10 codes.

The ethics committee of the Pirkanmaa health care district, Finland reviewed the study protocol (tracking numbers R03209 and R09159).

Statistical analysis. Cox proportional hazards regression was used to estimate hazard ratios (HR) and 95\% confidence intervals (CIs) for prostate cancer by medication usage. Nonusers of any NSAIDs (analyses on overall NSAID use) or nonusers of the drug/drug group being analysed (analyses on aspirin, coxibs and acetaminophen) were used as a reference group. Each man in the study population contributed person-time from the date of the randomisation until the date of prostate cancer diagnosis, emigration, death or end of study (31 December2009), whichever came first.

Cox regression model was adjusted for age, family history of prostate cancer, simultaneous use of other medications previously linked with prostate cancer risk (drugs used for benign prostatic hyperplasia, diabetes, hypercholesterolaemia and hypertension) and number of screening rounds attended. All, with the exception of family history, were statistically significant predictors of the outcome and included in the model. Analyses of the full trial cohort (both study arms together) were additionally adjusted for the trial arm. Analyses on aspirin, coxib or acetaminophen users were also adjusted for usage of other NSAIDs. The proportionality assumption was tested for time-independent variables by adding an interaction term of the exposure indicator with follow-up time into 


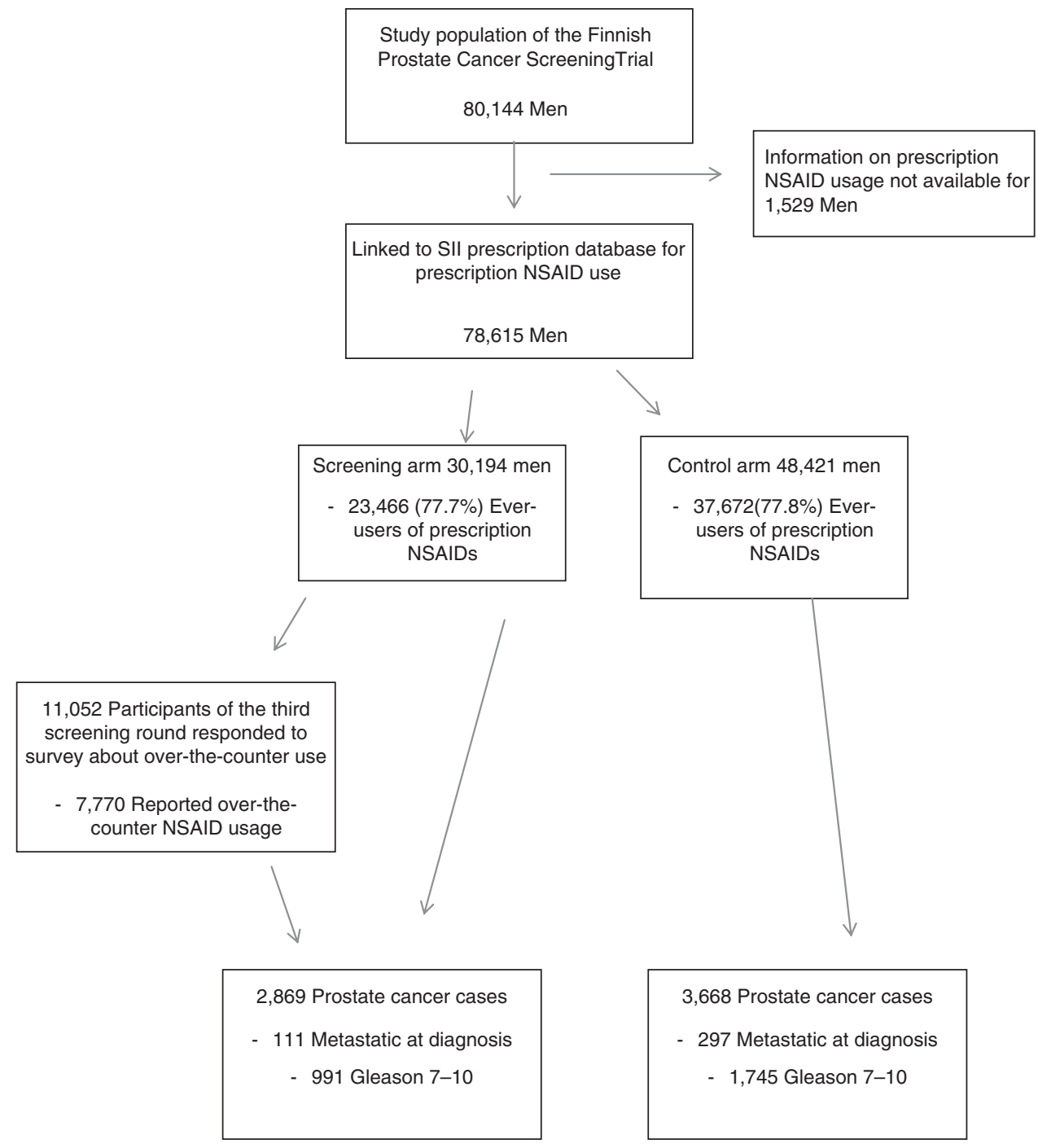

Figure 1. Flow diagram of the study population.

the Cox regression model. In each case the interaction term was not statistically significant, thus supporting the assumption.

The time axis was years since randomisation. Age and NSAID use were included in the Cox regression model as time-dependent variables, with status updated annually. Men were considered as NSAID nonusers until the year of first purchase. Years with medication purchases were considered as exposed regardless of the dose (current users). Men who stopped using NSAIDs were categorised separately as previous users. No restrictions on frequency of changes in exposure status were imposed, and the exposure status changed as often as the drug purchases indicated.

Cumulative amount (daily doses), duration (years) and intensity (doses/years of usage) of medication use were analysed as timedependent continuous variables. The defined daily doses (DDDs) recommended by the World Health Organization (WHO ATC/ DDD index database) were used to quantify and standardise the amount of NSAID usage. For each year, the total milligram amount for each drug was calculated based on all purchases reimbursed that year. Yearly usage was divided by the DDD amount. The total cumulative numbers of DDDs and years of usage were obtained by adding together yearly DDDs or years with NSAID purchases from the entire follow-up. The intensity of NSAID use was calculated by dividing the yearly number of DDDs purchased with years of usage (number of DDDs/year). Previous NSAID users retained the level of cumulative usage they had reached before discontinuation.
For analyses of dose-dependence, trend tests were calculated by limiting the analysis to medication users only, and adding the quartiles of amount, duration or intensity of usage into the multivariable-adjusted model as a continuous time-dependent variable.

A total cumulative COX-2 inhibition index by NSAID usage was calculated for each person by multiplying the total amount of each NSAID used with the drug-specific COX-1/COX-2 inhibition ratio (Cryer and Feldman, 1998; Kulkarni et al, 2000). The analysis was then stratified by cumulative COX-2 inhibition.

To reduce confounding by differing likelihood for NSAID use, we used logistic regression to calculate propensity score estimating each participant's conditional probability (odds ratio) of NSAID usage post randomisation as a function of age, use of other medications previously linked with prostate cancer risk and prerandomisation NSAID usage. Propensity from each variable was used to form total propensity score as described previously (Rosenbaum and Rubin, 1984). The analysis was then stratified by total propensity score.

To estimate effect modification by usage of medications for other indications, we stratified the analysis by ever use of BPH medication ( $5 \alpha$-reductase inhibitors and alpha-blockers), antidiabetic medication (oral drugs and insulins), cholesterol-lowering medication (statins, fibric acid derivatives, ezetimibe and bile acid-binding resins) and antihypertensive medication (diuretics, 
beta-blockers, calcium-channel blockers and drugs targeting the renin-angiotensin system). Effect modification by underlying comorbidities was evaluated using Charlson comorbidity score index calculated based on comorbidities (obtained either from HILMO or by usage of other medications).

Cox regression analyses were performed using IBM SPSS statistics statistical software (version 20, Chicago, IL, USA). Adjusted means for PSA values were estimated using STATA version 12 (StataCorp LP, College Station, TX, USA).

\section{RESULTS}

Population characteristics. The median age at entry was 59 years (range 55-67 years) for both NSAID users and nonusers (Table 1). The prevalence of ever use of prescription NSAIDs during followup was $77.7 \%$ in the screening arm and $74.7 \%$ in the control arm, whereas the prevalence was $7.3 \%$ and $7.1 \%$ for aspirin use and $35.7 \%$ and $35.4 \%$, respectively for NSAID usage before randomisation. The self-reported prevalence of over-the-counter use after 1990s was $70.3 \%$ for NSAIDs and $48.5 \%$ for aspirin.

Overall, the tumour characteristics did not differ by NSAID usage (Table 1). Ever users of prescription NSAIDs had more often used drugs for other indications in both screening trial arms. The proportions of screen-positive men were greater for NSAID users $v s$ nonusers in all screening rounds (Supplementary Table 2).

Overall prostate cancer risk. When compared with NSAID nonusers, the overall prostate cancer risk was elevated among current NSAID prescription users $(\mathrm{HR}=1.45,95 \% \mathrm{CI}=1.33-1.59$ and $\mathrm{HR}=1.32,95 \% \mathrm{CI}=1.10-1.59$ in the screening and the control arm, respectively). Previous use or over-the-counter use was not associated with prostate cancer risk. A similar risk association was observed also for acetaminophen, but not for aspirin. Both current and previous coxib use was associated with elevated prostate cancer risk (Tables $2 \mathrm{a}$ and $\mathrm{b}$ ).

Prostate cancer risk by tumour stage and grade. Current, but not previous use of prescription NSAIDs, coxibs and acetaminophen associated with an elevated risk of metastatic prostate cancer in both trial arms (Tables 2a and b). Again, aspirin use was not significantly associated with metastatic prostate cancer risk, with the exception of elevated risk among prescription users in the control arm.

The increased prostate cancer risk associated with overall NSAID, coxib and acetaminophen use was not modified by tumour grade; the risk elevation with current NSAID use was similar for low-grade (Gleason 6 or less) and high-grade (Gleason 7-10) tumours in both arms of the screening trial (Tables $2 \mathrm{a}$ and $\mathrm{b}$ ).

Prostate cancer risk by cumulative dose, duration and intensity of usage. Both the overall prostate cancer risk and the risk of metastatic disease were elevated in all quartiles of amount or duration of prescription NSAID and coxib use showing no obvious exposure-effect gradient (Table 3). Intensity of NSAID and coxib use was directly correlated with risk of metastatic prostate cancer after adjustment for the use of other drugs.

The association between aspirin prescription-use and prostate cancer remained statistically nonsignificant in all strata (Table 3).

Sensitivity analyses. The association between NSAID use and prostate cancer risk was not modified by cumulative COX-2 inhibition; the risk was elevated in each quartile of the cumulative COX-2 inhibition, both overall and metastatic disease (Supplementary Table 3).

Stratification by the use of other drug groups or NSAIDs before randomisation, Charlson comorbidity index or propensity for

Table 1. Population characteristics of men attending the Finnish prostate screening trial and the control arm

\begin{tabular}{|c|c|c|c|c|}
\hline \multirow[b]{2}{*}{ Characteristics of participants } & \multicolumn{2}{|c|}{ Screening arm } & \multicolumn{2}{|c|}{ Control arm } \\
\hline & NSAID users & NSAID nonusers & NSAID users & NSAID nonusers \\
\hline Number of participants & 23466 & 6728 & 37672 & 10749 \\
\hline Age at randomisation; median (range) & $59(55-67)$ & $59(55-67)$ & $59(55-67)$ & $59(55-67)$ \\
\hline Age at diagnosis; median (range) & $67(55-80)$ & $66(55-79)$ & $68(55-80)$ & $67(55-79)$ \\
\hline Mean body mass index & 26.9 & 26.0 & - & - \\
\hline Years of follow-up; median (range) & $12(0-14)$ & $11(0-14)$ & $12(0-14)$ & $11(0-14)$ \\
\hline Prostate cancer diagnoses between randomisation and 31 December 2009 & 2410 & 459 & 3181 & 487 \\
\hline Gleason 6 or less; $n$ (\% of diagnoses) & $1546(64.1)$ & $292(63.6)$ & $1548(48.7)$ & $236(48.5)$ \\
\hline Gleason 7-10; n (\%) & $833(34.6)$ & $158(34.4)$ & $1522(47.8)$ & $223(45.8)$ \\
\hline Metastatic disease at Dx; $n(\%)^{a}$ & $93(3.9)$ & $18(3.9)$ & $252(7.9)$ & $45(9.2)$ \\
\hline \multicolumn{5}{|l|}{ Prevalence of medication use } \\
\hline $\begin{array}{l}\text { Benign prostatic hyperplasia drugs; } n(\%)^{\mathbf{b}} \\
\text { Antidiabetic drugs; } n(\%)^{\mathbf{c}} \\
\text { Cholesterol-lowering drugs; } n(\%)^{\mathbf{d}} \\
\text { Antihypertensive drugs; } n(\%)^{\mathbf{e}}\end{array}$ & $\begin{array}{r}7931(33.8) \\
5166(22.0) \\
11174(47.6) \\
16963(72.3)\end{array}$ & $\begin{array}{l}1047(15.6) \\
1002(14.9) \\
1672(24.9) \\
3490(51.9)\end{array}$ & $\begin{array}{r}12861(35.7) \\
7773(21.6) \\
16830(46.7) \\
25742(71.4)\end{array}$ & $\begin{array}{l}2160(20.1) \\
1952(18.2) \\
3550(33.0) \\
6736(62.7)\end{array}$ \\
\hline \multicolumn{5}{|c|}{ 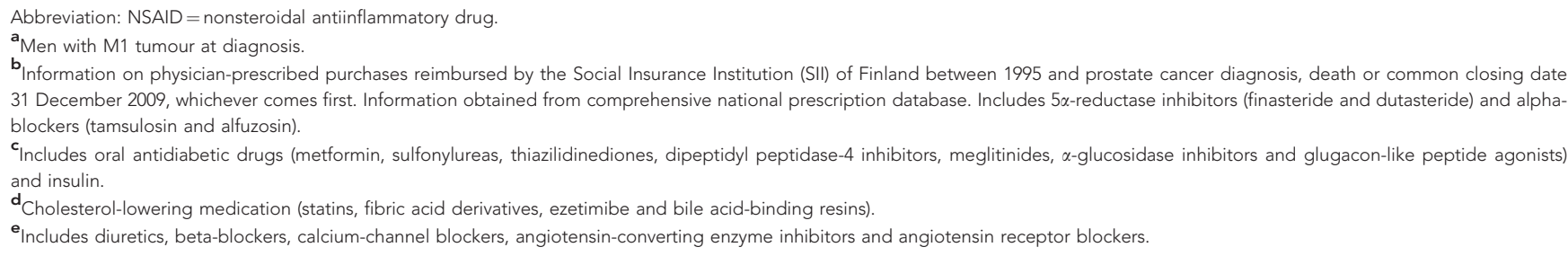 } \\
\hline
\end{tabular}




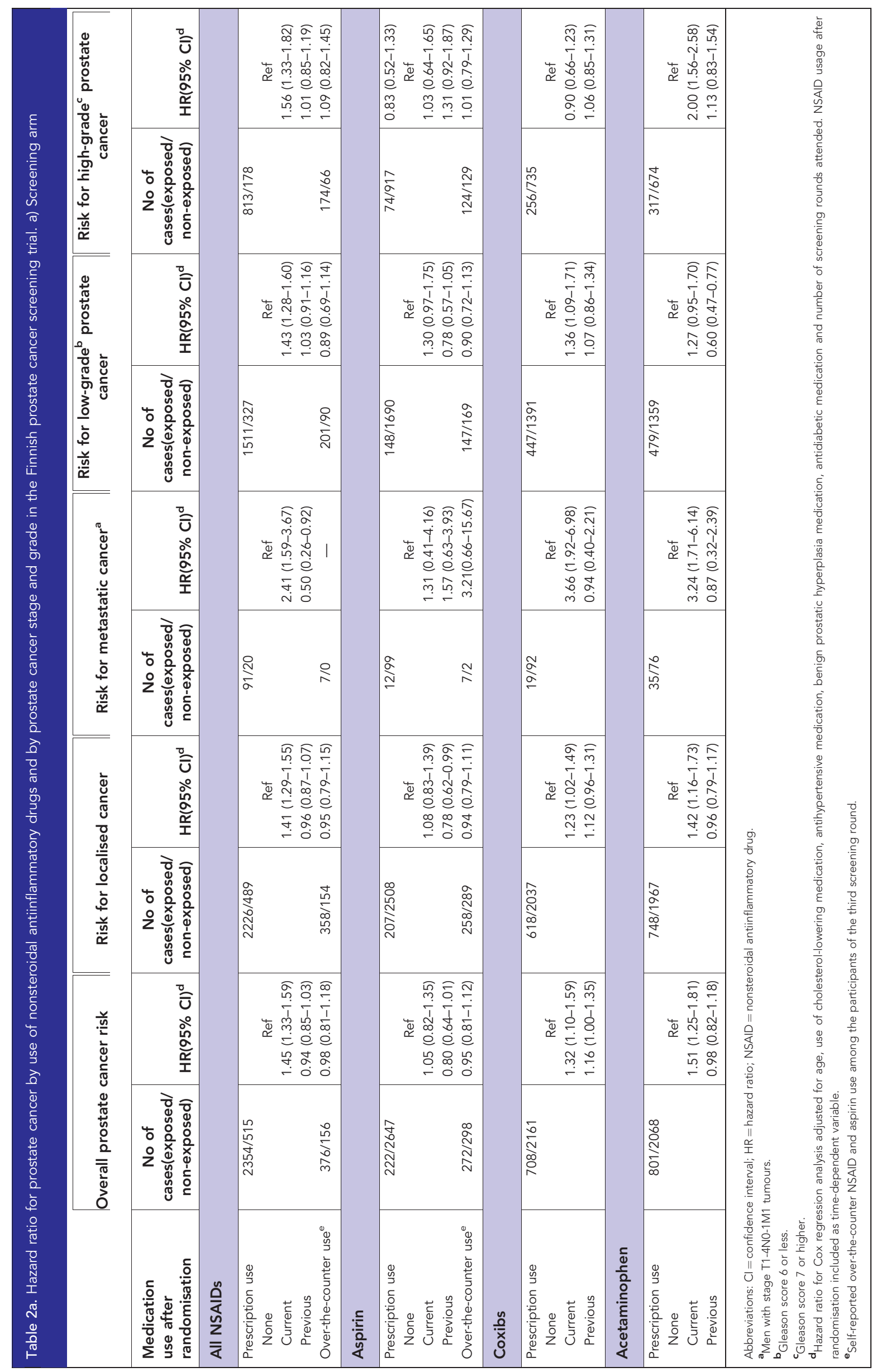




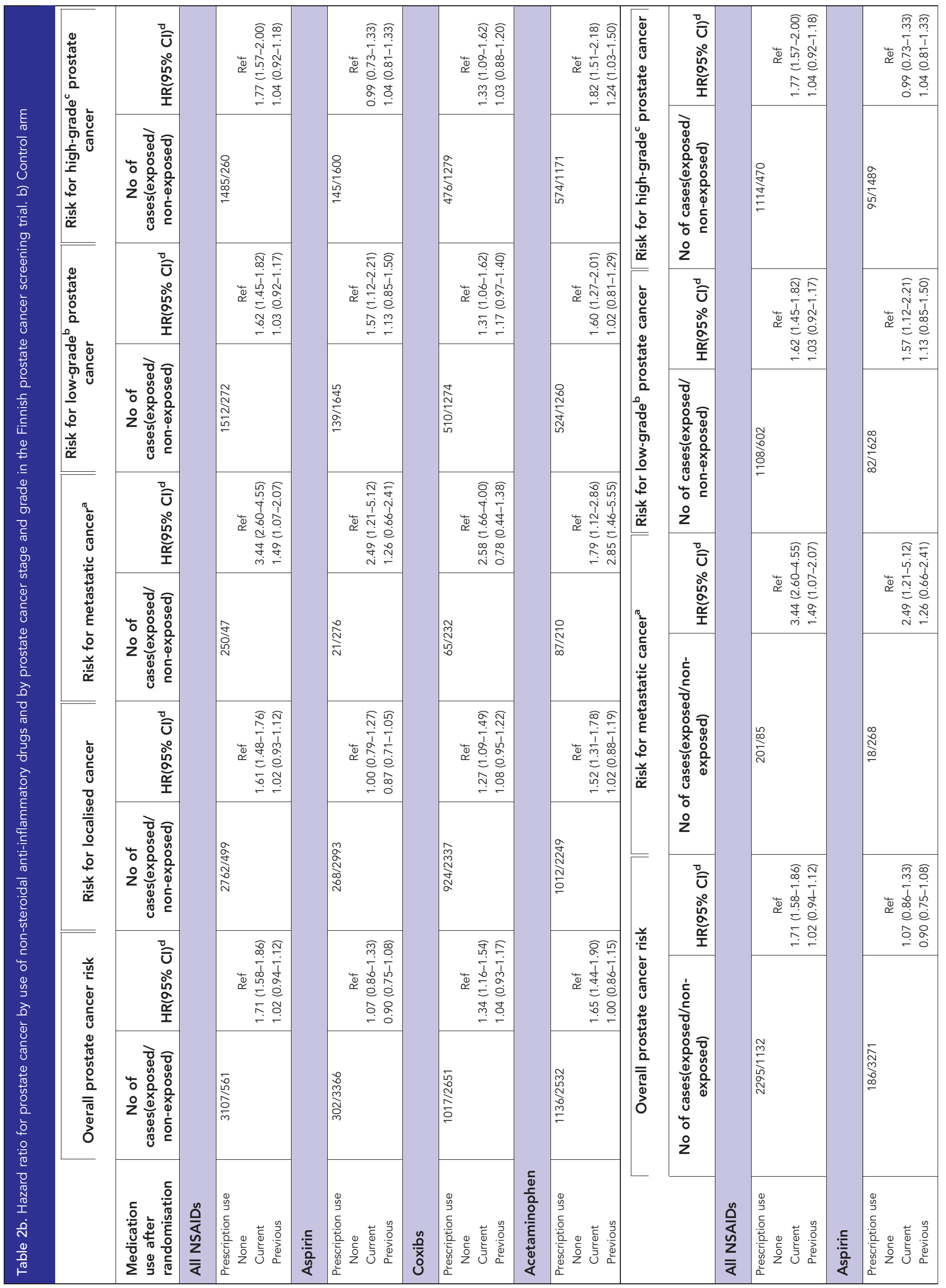




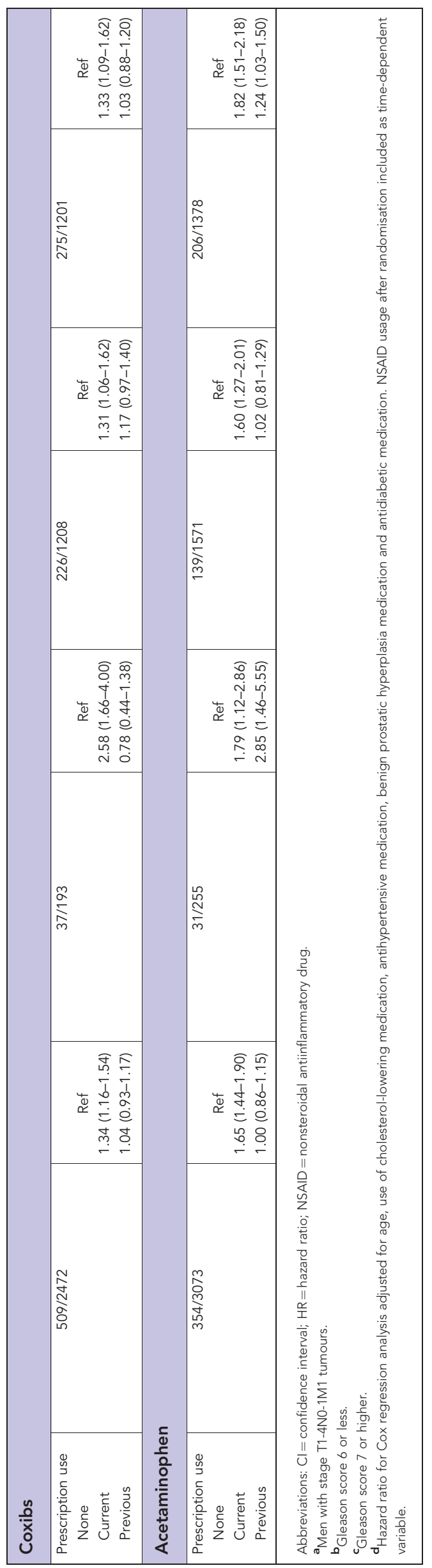

NSAID use did not modify the risk association with prostate cancer; current NSAID users had elevated prostate cancer risk, especially for metastatic disease whereas the risk in aspirin users did not differ from nonusers (Table 4).

DISCUSSION

Our study showed an increased HR for prostate cancer among the current prescription users of NSAIDs, coxibs and acetaminophen, but not in men who had been able to discontinue usage, the previous users. Over-the-counter NSAID usage was not associated with prostate cancer risk, either.

Unlike other NSAIDs, aspirin use whether by prescription or over-the-counter was not associated with prostate cancer risk.

Previous results on risk of prostate cancer and other cancer types among NSAID users have been conflicting; whereas some studies have shown an inverse association (Mahmud et al, 2010), also null associations (Leitzmann et al, 2002; Brasky et al, 2010) and increased risks have been reported in both case-control and population-based settings. (Langman et al, 2000; Sørensen et al, 2003; Murad et al, 2011). In our previous study (Veitonmäki et al, 2013) in a nationwide population-based setting, we found an elevated risk for prostate cancer in prescription NSAID users. A large case-control study (within the ProtecT trial) reported that prescription NSAID use was associated with prostate cancer (Murad et al, 2011), with weaker positive associations for aspirin and acetaminophen. In another case-control study increased risks of pancreatic cancer and prostatic cancer among current prescription NSAID users was observed, but a dose response was found only for pancreatic cancer (Langman et al, 2000). An increased risk for cancers of the prostate, kidney and for multiple myeloma was reported among prescription non-aspirin NSAID users in a population-based study (Sørensen et al, 2003). Some studies have reported NSAID use to associate to an increased risk for several other cancers (Cho et al, 2011; Ross et al, 2011; Vinogradova et al, 2011; Walter et al, 2011). Our findings could help explain some of the previous discrepancy in results, as the association between NSAID use and prostate cancer differed between prescription and over-the-counter use, and most previous studies have used either surveys or prescription databases and have not been able to address this difference. Future epidemiological studies on NSAIDs and prostate cancer risk should consider the two separately.

Our findings do not support a causal association between NSAID use and prostate cancer as the risk elevation was observed only for ongoing prescription use, was strongest for metastatic disease and did not differ by amount or duration of usage. This demonstrates that men starting use of prescription-NSAIDs are at higher risk of prostate cancer, especially metastatic disease already when commencing the use. A comparable risk elevation was observed also for acetaminophen use, with largely similar indications for usage, but a different mechanism of action. Thus the risk elevation is most likely caused by protopathic bias due to treatment of symptoms of undiagnosed prostate cancer, presumably mainly pain due to metastases. This is supported by greatest risk elevation for metastatic cancer being observed with short-term and high-intensity use. Nevertheless, a modest risk elevation by current NSAID and coxib use was observed also for localised and low-grade prostate cancer. This was evident in both study arms of the screening trial, thus not likely explained by more active screening among NSAID users. Again the risk elevation was not dose-dependent suggesting that the indications for NSAID usage are behind this association too.

Common indications for NSAIDs include acute minor infections and chronic inflammatory conditions. It is possible that the systemic inflammation involved in these conditions is involved in 
Table 3. Hazard ratio for overall prostate cancer risk by amount and duration of prescription-use of non-steroidal anti-inflammatory drugs among men participating in the Finnish prostate cancer screening trial during 1996-2009
All NSAIDs
Aspirin
Coxibs

\begin{tabular}{|c|c|c|c|c|c|c|}
\hline $\begin{array}{l}\text { Quantity/ } \\
\text { duration of } \\
\text { medication use }\end{array}$ & $\begin{array}{l}\mathrm{HR}(95 \% \mathrm{Cl})^{\mathrm{a}} \\
\text { Overall } \mathrm{PCa}\end{array}$ & $\begin{array}{c}\mathrm{HR}(95 \% \mathrm{Cl}) \\
\text { Metastatic PCa }\end{array}$ & $\begin{array}{l}\mathrm{HR}(95 \% \mathrm{Cl})^{\mathrm{a}} \\
\text { Overall } \mathrm{PCa}\end{array}$ & $\begin{array}{c}\mathrm{HR}(95 \% \mathrm{Cl}) \\
\text { Metastatic PCa }\end{array}$ & $\begin{array}{l}\mathrm{HR}(95 \% \mathrm{Cl})^{a} \\
\text { Overall } \mathrm{PCa}\end{array}$ & $\begin{array}{c}\mathrm{HR}(95 \% \mathrm{Cl}) \\
\text { Metastatic PCa }\end{array}$ \\
\hline \multicolumn{7}{|c|}{ Cumulative quantity of medication use $^{b}$} \\
\hline \multicolumn{7}{|l|}{ DDD quartiles } \\
\hline 1 & $1.24(1.16-1.33)$ & 1.35 (1.01-1.82) & $0.92(0.69-1.22)$ & $1.05(0.34-3.27)$ & $1.07(0.93-1.22)$ & $0.83(0.43-1.56)$ \\
\hline 2 & $1.35(1.26-1.45)$ & $1.78(1.32-2.40)$ & $0.99(0.84-1.17)$ & $1.77(1.03-3.04)$ & $1.21(1.06-1.38)$ & $1.17(0.67-2.04)$ \\
\hline 3 & $1.29(1.20-1.40)$ & $2.42(1.80-3.24)$ & $0.88(0.70-1.10)$ & $0.89(0.33-2.40)$ & $1.17(1.02-1.34)$ & $1.54(0.94-2.53)$ \\
\hline 4 & $1.20(1.10-1.31)$ & $1.72(1.22-2.43)$ & $0.93(0.74-1.16)$ & $1.11(0.46-2.70)$ & $1.04(0.90-1.20)$ & $1.42(0.85-2.38)$ \\
\hline$P$ for trend & 0.153 & 0.943 & 0.296 & 0.822 & 0285 & 0.943 \\
\hline
\end{tabular}

Duration of medication use ${ }^{c}$

Year quartiles $^{\mathrm{d}}$

\begin{tabular}{|c|c|c|c|c|c|c|}
1 & $1.31(1.22-1.39)$ & $2.08(1.63-2.65)$ & $0.95(0.82-1.11)$ & $1.67(1.01-2.77)$ & $1.13(1.04-1.23)$ & $1.42(1.02-1.96)$ \\
2 & $1.26(1.18-1.36)$ & $1.55(1.16-2.06)$ & $0.92(0.74-1.15)$ & $1.10(0.45-2.66)$ & $1.10(0.97-1.24)$ & $0.81(0.45-1.46)$ \\
3 & $1.24(1.13-1.36)$ & $1.27(0.84-1.92)$ & $1.07(0.81-1.39)$ & $1.12(0.36-3.49)$ & \\
4 & $1.19(1.07-1.33)$ & $0.97(0.59-1.60)$ & $0.82(0.61-1.09)$ & $0.67(0.17-2.71)$ & \\
$P$ for trend & 0.893 & 0.151 & 0.280 & 0.628 & 0.146 & 0.980 \\
\hline
\end{tabular}

Intensity of medication use (DDDs per year)

Intensity quartile

\begin{tabular}{|c|c|c|c|c|c|c}
1 & $1.26(1.17-1.35)$ & $1.25(0.92-1.70)$ & $0.97(0.77-1.23)$ & $0.80(0.25-2.47)$ & $1.05(0.92-1.20)$ & $0.77(0.41-1.45)$ \\
2 & $1.25(1.16-1.36)$ & $1.36(0.95-1.93)$ & $1.01(0.84-1.22)$ & $1.65(0.88-3.12)$ & $1.27(1.11-1.45)$ \\
3 & $1.29(1.20-1.40)$ & $1.70(1.24-2.33)$ & $0.81(0.64-1.04)$ & $1.72(0.81-3.67)$ & $1.19(1.03-1.36)$ \\
4 & $1.30(1.20-1.40)$ & $2.79(2.13-3.65)$ & $0.94(0.77-1.14)$ & $1.03(0.46-2.32)$ & $1.02(0.89-1.17)$ \\
$P$ for trend & 0.870 & $<0.001$ & 0.344 & $0.691-2.20)$ \\
\hline
\end{tabular}

Abbreviations: $\mathrm{Cl}=$ confidence interval; $\mathrm{HR}=$ hazard ratio; $\mathrm{NSAID}=$ nonsteroidal antiinflammatory drug; $\mathrm{PCa}=$ prostate cancer

${ }^{a_{H}}$ azard ratios of prostate cancer from Cox regression analysis adjusted for age, use of cholesterol-lowering medication, antihypertensive medication, benign prostatic hyperplasia medication and antidiabetic medication and the screening trial arm.

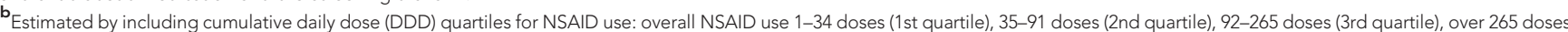
(4th quartile); aspirin 1-3.5 doses (1st quartile), 3.6-10 doses (2nd quartile), 11-23 doses (3rd quartile), 24 of more doses (4th quartile); coxibs 1-21 doses (1st quartile), 22-49 doses (2nd quartile), 50-130 doses (3rd quartile), over 130 doses (4th quartile).

'Quartiles for duration of NSAID use before diagnosis: overall NSAID use 1 year (1st quartile), over 1 to 3 years (2nd quartile), over 3 to 5 years ( 3 rd quartile) and over 5 years (4th quartile). Use of aspirin before diagnosis 1 year (1st quartile), 2 years (2nd quartile), 3 years (3rd quartile), 4 or over years (4th quartile). Use of coxibs: 1 year and 2 years or longer.

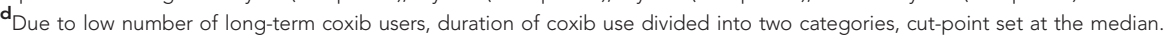

e Quartile cut-points: overall NSAID use: 2-20 DDDs per year (1st quartile), 21-34 DDDs per year (2nd quartile), 35-67 DDDs per year (3rd quartile) and 68 DDDs pe ryear or more (4th quartile); Aspirin use: 0.25-3 DDDs per year (1st quartile), 4-5 DDDs per year (2nd quartile), 6-7 DDDs per year (3rd quartile), 7 DDDs per year or more (4th quartile); Coxib use: 7-20 DDDs per year (1st quartile), 21-35 DDDs per year (2nd quartile), 36-82 DDDs per year (3rd quartile) or 83 DDDs per year or more (4th quartile).

prostate carcinogenesis and prostate cancer progression. Prostatitis might be involved in the complex and multifactorial process of prostate carcinogenesis (MacLennan et al, 2006; Wagenlehner et al, 2007; Sfanos and De Marzo, 2012). Chronic prostatic inflammation may have a role in the development and progression of chronic prostatic disease, such as $\mathrm{BPH}$ and prostate carcinoma (De Nunzio et al, 2011). The role of inflammation in prostate cancer can possibly be explained through the cytokine pathway. Interleukin-6 (IL-6) is cytokine that is involved in numerous inflammatory processes (Hirano, 1992) and multiple lines of evidence point to a contributory role in prostate cancer initiation and progression (Twillie et al, 1995; Hobisch et al, 2000; Smith et al, 2001). IL-6 induces the expression of the serine peptidase inhibitor Kazal type 1 (SPINK1) that is overexpressed in prostate cancer (Stenman, 2011) and has been linked to a poorer outcome (Tomlins et al, 2008). Another possible biochemical explanation could be the nonsteroidal antiinflammatory drug (NSAID) activated gene-1. NAG-1 has a complex but poorly understood role in several human diseases including cancer. Laboratory studies suggest an antitumorigenic activity of NAG-1 that induces growth arrest or apoptosis, whereas clinical studies demonstrate that NAG-1 expression is upregulated in human prostate cancers, which may also correlate with tumour grade and progression. NAG-1 may have an antitumorigenic role at the early stages of carcinogenesis, but a pro-tumorigenic one during cancer progression (Wang et al, 2013). Chronic inflammation and several systematic rheumatic diseases might also be risk factors for malignancy (Coussens and Werb, 2002; Turesson and Matteson, 2013), though the findings regarding prostate cancer are conflicting.

In contrast to other types of NSAIDs, aspirin use was not associated with increased prostate cancer risk. Unlike other NSAIDs, prescription aspirin is mainly used for prevention of cardiovascular and cerebrovascular disorders, and less often as analgetic. The prescription aspirin use in our study population was mostly in combination with dipyridamole for secondary prevention of stroke or transient ischaemic attack (The European Stroke Association (ESO) Executive Committee and the ESO Writing Committee, 2008). Another common indication for aspirin use is cardiovascular disease prevention, for which it is used mainly overthe-counter. These users are more likely to be health-conscious men using small-dose aspirin for preventive reasons, combining aspirin use with healthier lifestyle in general compared with 
Table 4. Multivariable-adjusted hazard ratios for overall and metastatic prostate cancer risk for NSAID prescription usage stratified by medication use, Charlson comorbidity index and propensity score

\begin{tabular}{|c|c|c|c|c|c|c|c|c|c|c|}
\hline \multirow[b]{3}{*}{$\begin{array}{l}\text { Prescription } \\
\text { drug use }\end{array}$} & \multicolumn{2}{|c|}{ BPH medication ${ }^{a}$} & \multicolumn{2}{|c|}{$\begin{array}{c}\text { Cholesterol-lowering } \\
\text { medication }^{\mathrm{b}}\end{array}$} & \multicolumn{2}{|c|}{$\begin{array}{l}\text { Antihypertensive } \\
\text { medication }^{c}\end{array}$} & \multicolumn{2}{|c|}{$\begin{array}{l}\text { Antidiabetic } \\
\text { medication }^{d}\end{array}$} & \multicolumn{2}{|c|}{$\begin{array}{l}\text { pre-randomisation } \\
\text { NSAID }^{\mathrm{e}} \text { use }\end{array}$} \\
\hline & \multicolumn{2}{|c|}{$\operatorname{HR}(95 \% \mathrm{Cl})^{f}$} & \multicolumn{2}{|c|}{$\mathrm{HR}(95 \% \mathrm{Cl})$} & \multicolumn{2}{|c|}{ HR $(95 \% \mathrm{Cl})$} & \multicolumn{2}{|c|}{ HR $(95 \% \mathrm{Cl})$} & \multicolumn{2}{|c|}{$\mathrm{HR}(95 \% \mathrm{Cl})$} \\
\hline & Yes & No & Yes & No & Yes & No & Yes & No & yes & no \\
\hline
\end{tabular}

\section{Overall prostate cancer risk}

NSAID

\begin{tabular}{|c|c|c|c|c|c|c|c|c|c|c|}
\hline $\begin{array}{l}\text { Never } \\
\text { Current }\end{array}$ & $\begin{array}{c}\operatorname{Ref} \\
1.37(1.26-1.50)\end{array}$ & $\begin{array}{c}\operatorname{Ref} \\
1.76(1.63-1.92)\end{array}$ & $\begin{array}{c}\operatorname{Ref} \\
1.39(1.27-1.51)\end{array}$ & $\begin{array}{c}\operatorname{Ref} \\
1.80(1.66-1.95)\end{array}$ & $\begin{array}{c}\operatorname{Ref} \\
1.47(1.37-1.57)\end{array}$ & $\begin{array}{c}\operatorname{Ref} \\
1.98(1.77-2.22)\end{array}$ & $\begin{array}{c}\operatorname{Ref} \\
1.38(1.20-1.58)\end{array}$ & $\begin{array}{c}\operatorname{Ref} \\
1.66(1.55-1.77)\end{array}$ & $\begin{array}{c}\text { ref } \\
1.38(1.24-1.53)\end{array}$ & $\begin{array}{c}\text { ref } \\
1.78(1.65-1.92\end{array}$ \\
\hline \multicolumn{11}{|l|}{ Aspirin } \\
\hline $\begin{array}{l}\text { never } \\
\text { current }\end{array}$ & $\begin{array}{c}\operatorname{Ref} \\
0.92(0.73-1.16)\end{array}$ & $\begin{array}{c}\operatorname{Ref} \\
1.27(1.01-1.60)\end{array}$ & $\begin{array}{c}\operatorname{Ref} \\
1.02(0.84-1.24)\end{array}$ & \begin{tabular}{c|}
$\operatorname{Ref}$ \\
$1.33(0.97-1.82)$
\end{tabular} & \begin{tabular}{c|}
$\operatorname{Ref}$ \\
$1.11(0.94-1.32)$
\end{tabular} & \begin{tabular}{c|} 
Ref \\
$0.87(0.48-1.58)$
\end{tabular} & \begin{tabular}{|c|}
$\operatorname{Ref}$ \\
$0.87(0.63-1.20)$
\end{tabular} & \begin{tabular}{|c|}
$\operatorname{Ref}$ \\
$1.18(0.98-1.42)$
\end{tabular} & $\begin{array}{c}\text { ref } \\
1.09(0.86-1.38)\end{array}$ & $\begin{array}{c}r e f \\
1.05(0.84-1.32\end{array}$ \\
\hline
\end{tabular}

\section{Risk of metastatic ${ }^{9}$ prostate cancer}

\begin{tabular}{|c|c|c|c|c|c|c|c|c|c|c|}
\hline \multicolumn{11}{|l|}{ NSAID } \\
\hline Current & $2.10(1.44-3.07)$ & \begin{tabular}{|l|l|}
$.07)$ & $2.96(2.22-3.96)$ \\
\end{tabular} & $2.29(1.49-3.54)$ & $2.84(2.16-3.73)$ & $2.57(1.96-3.36)$ & $2.82(1.80-4.42)$ & $2.51(1.51-4.18)$ & $2.67(2.06-3.46)$ & $2.59(1.56-4.31)$ & $3.24(2.47-4.25)$ \\
\hline \multicolumn{11}{|l|}{ Aspirin } \\
\hline \multirow[t]{4}{*}{ Current } & $1.54(0.67-3.52)$ & \begin{tabular}{|l|l|}
$3.52)$ & $1.34(0.55-3.28)$ \\
\end{tabular} & $1.62(0.78-3.34)$ & $1.14(0.37-3.57)$ & $1.56(0.85-2.87)$ & - & $2.12(0.92-4.92)$ & $|1.05(0.43-2.56)|$ & $1.88(0.81-4.36)$ & \begin{tabular}{|l|l|}
$1.11(0.45-2.71)$ \\
\end{tabular} \\
\hline & & \multicolumn{9}{|c|}{ Charlson comorbidity index } \\
\hline & & \multicolumn{3}{|c|}{$0 \mathrm{HR}(95 \% \mathrm{Cl})^{f}$} & \multicolumn{3}{|c|}{ 1-2 HR $(95 \% \mathrm{Cl})$} & \multicolumn{3}{|c|}{3 or more HR $(95 \% \mathrm{Cl})$} \\
\hline & & $\begin{array}{l}\text { Overall PCa } \\
\text { risk }\end{array}$ & $\begin{array}{l}\text { Risk for me } \\
\mathrm{PCa}^{9}\end{array}$ & tastatic & $\begin{array}{l}\text { Overall PCa } \\
\text { risk }\end{array}$ & $\begin{array}{r}\text { Risk for } \\
P\end{array}$ & $\begin{array}{l}\text { metastatic } \\
\mathrm{Ca}^{\mathrm{g}}\end{array}$ & $\begin{array}{c}\text { Overall } P C a \\
\text { risk }\end{array}$ & Risk fo & $\begin{array}{l}\text { or metastatic } \\
\mathrm{PCa}^{9}\end{array}$ \\
\hline Prescrip & ig use & $\mathrm{HR}(95 \% \mathrm{Cl})^{f}$ & $\mathrm{HR}(95 \%$ & $6 \mathrm{Cl})^{f}$ & $\mathrm{HR}(95 \% \mathrm{Cl})^{f}$ & $\mathrm{HR}(\mathrm{C}$ & $95 \% \mathrm{Cl})^{f}$ & $\mathrm{HR}(95 \% \mathrm{Cl})^{\dagger}$ & & $R(95 \% C l)^{f}$ \\
\hline \multicolumn{11}{|l|}{ NSAID } \\
\hline \multicolumn{2}{|l|}{ Current } & $1.73(1.60-1.89)$ & \multicolumn{2}{|c|}{$2.29(2.13-4.03)$} & $1.47(1.32-1.64)$ & \multicolumn{2}{|c|}{$2.33(1.56-3.47)$} & \multicolumn{3}{|c|}{$2.09(1.12-3.89)$} \\
\hline \multicolumn{11}{|l|}{ ASA } \\
\hline \multirow{4}{*}{\multicolumn{2}{|c|}{ Current }} & \multicolumn{3}{|c|}{$1.43(0.35-5.81)$} & $1.17(0.94-1.46)$ & \multicolumn{2}{|c|}{$1.15(0.46-2.83)$} & \multicolumn{3}{|c|}{$1.51(0.38-4.27)$} \\
\hline & & \multicolumn{9}{|c|}{ Propensity score ${ }^{i}$} \\
\hline & & \multicolumn{3}{|c|}{ 1st tertile } & \multicolumn{3}{|c|}{ 2nd tertile } & \multicolumn{3}{|c|}{ 3rd tertile } \\
\hline & & $\begin{array}{l}\text { Overall } \\
\text { PCa risk }\end{array}$ & $\begin{array}{r}\text { Risk fo } \\
\text { metastatic }\end{array}$ & $\begin{array}{l}\text { or } \\
c \mathrm{PCa}^{\mathrm{g}}\end{array}$ & $\begin{array}{l}\text { Overall } \\
\text { PCa risk }\end{array}$ & $\begin{array}{r}\text { Ris } \\
\text { metast }\end{array}$ & $\begin{array}{l}k \text { for } \\
\text { atic } \mathrm{PCa}^{\mathrm{g}}\end{array}$ & $\begin{array}{l}\text { Overall } \\
\text { pca risk }\end{array}$ & $\begin{array}{r}\mathrm{R} \\
\text { metas }\end{array}$ & $\begin{array}{l}\text { Risk for } \\
\text { astatic } \mathrm{PCa}^{\mathrm{g}}\end{array}$ \\
\hline Prescrip & Ig use & HR $(95 \% \mathrm{Cl})^{f}$ & HR $(95 \%$ & $6 \mathrm{Cl})^{f}$ & $\mathrm{HR}(95 \% \mathrm{Cl})^{\mathrm{f}}$ & HR $(9$ & $5 \% \mathrm{Cl})^{f}$ & HR $(95 \% \mathrm{Cl})^{f}$ & & $(95 \% \mathrm{Cl})^{f}$ \\
\hline \multicolumn{11}{|l|}{ NSAID } \\
\hline Current & & $2.11(1.86-2.40)$ & $3.77(2.58-$ & $-5.53)$ & $1.61(1.47-1.77)$ & $3.04(2$ & .08-4.45) & $1.37(1.23-1.53)$ & 2.29 & $9(1.38-3.80)$ \\
\hline \multicolumn{11}{|l|}{ ASA } \\
\hline Current & & $1.17(0.66-2.07)$ & $1.20(0.17-$ & $-8.63)$ & $0.99(0.76-1.29)$ & $0.92(0$ & $.29-2.90)$ & $1.15(0.92-1.43)$ & 2.05 & $5(0.94-4.46)$ \\
\hline $\begin{array}{l}\text { Abbreviati } \\
\mathrm{a}_{\mathrm{BPH} \text { mec }} \\
\mathrm{b}_{\text {Antihype }} \\
{ }^{\mathrm{c}} \text { Choleste } \\
\mathrm{d}_{\text {Antidiab }} \\
\mathrm{e}_{\text {NSAID u }} \\
\mathrm{f}_{\text {Hazard ra }} \\
\text { trial arm. } \\
\mathbf{g}_{\text {Men with }} \\
\mathrm{h}_{\text {Charlson }} \\
\mathrm{i}_{\text {Propensit }}\end{array}$ & $\begin{array}{l}\text { = aspirin; } \\
\text { 5 } \alpha \text {-reducta } \\
\text { medicatior } \\
\text { ng medic } \\
\text { cation (or } \\
\text { us before } \\
\text { Cox reg } \\
11 \text { tumour } \\
\text { dity index } \\
\text { AID usage }\end{array}$ & $\begin{array}{l}\text { I = confidence interva } \\
\text { inhibitors and alpha- } \\
\text { diuretics, beta-blocke } \\
\text { on (statins, fibric acid } \\
\text { drugs and insulins). } \\
\text { e screening trial rand } \\
\text { sion analysis adjuste } \\
\text { diagnosis. } \\
\text { aculated and stratified } \\
\text { ter screening trial ran }\end{array}$ & $\begin{array}{l}\text {; } H R=\text { hazard rati } \\
\text { blockers). } \\
\text { rs, calcium-channe } \\
\text { derivatives, ezetin } \\
\text { omisation. } \\
\text { d for age, choles } \\
\text { into groups } 0 \mathrm{pc} \\
\text { domisation by bas }\end{array}$ & $\begin{array}{l}\text { sterol-lowering } n \\
\text { oints, 1-2 points } \\
\text { seline age, use }\end{array}$ & $\begin{array}{l}\text { medication, antihyp } \\
\text {, } 3 \text { points and ove } \\
\text { of other drug grou }\end{array}$ & $\begin{array}{l}\text { mmatory drug; } P C \\
\text { ne renin-angioten }\end{array}$ & $\begin{array}{l}\text { Ca }=\text { prostate canc } \\
\text { sin system). }\end{array}$ & ostatic hyperplasia & ia medication an & nd the screening \\
\hline
\end{tabular}


nonusers. Our results from this study do not support prostate cancer preventive effect of aspirin even in long-term use, although the general elevated risk association among NSAID users may have masked a modest risk decreasing effect.

The strength of our study is detailed and objective information on prescription NSAID purchases from the SII prescription database. In addition, we had self-reported information on overthe-counter NSAID usage, although for a shorter period for participants of the third screening round. Thus the results on prescription and over-the-counter usage may not be directly comparable. We had the comprehensive population-based data from the Finnish Cancer registry and the Finnish prostate screening trial with detailed information on prostate cancer grade and stage, and were able to evaluate prostate cancer risk among NSAID users in a setting of systematic screening, which reduces surveillance bias. Further, we could assess the impact of comorbidities and usage of other medication on the results. Thus we were able to minimise the possibility for information and misclassification bias.

Age, ethnic origin and hereditary factors are well-known risk factors for prostate cancer (Steinberg et al, 1990; Crawford, 2009). More than $98 \%$ of our study population is of Finnish ancestry (Statistics Finland) and the potential for confounding by ethnicity was minimal. Adjusting the analysis for family history did not change our results. We did not have the information on possible lifestyle risk factors such as dietary aspects, alcohol and tobacco consumption or physical activity. This could have caused confounding in either direction, depending on their association with prostate cancer risk. However, their role as prostate cancer risk factors is unclear (Patel and Klein, 2009).

The main limitation of our analysis is missing information on indications of NSAID use, making it difficult to analyse the reasons behind NSAID use. Our study shows that conditions requiring NSAID prescription use may affect prostate cancer risk. Future studies should address the indications for NSAID usage.

The prescription database gives detailed and objective exposure information eliminating recall bias. However, the analysis is based on the assumption that the amount of NSAIDs dispensed is a good approximation of the actual consumption. This may be not be true for NSAIDS that are often prescribed to be taken as needed and prescribed drugs may be used only partially or not at all. This might have caused exposure misclassification creating bias towards the null. However, it does not limit our inference of increased prostate cancer risk.

In conclusion, our study showed an elevated risk of prostate cancer in current NSAID prescription users, but not in previous or over-the-counter users. The result is likely to be mostly due to protopathic bias as NSAIDS are used to treat symptoms of undiagnosed metastatic prostate cancer. However, also risk of localised prostate cancer was elevated with current prescription use without dose-dependence, suggesting that conditions indicating such usage could be a prostate cancer risk factor. We found no protecting association for aspirin or NSAID use for prostate cancer. Future studies on NSAIDs and prostate cancer should separate over-the-counter or physician-prescribed use and consider indications for usage to reduce the discrepancy between studies.

\section{ACKNOWLEDGEMENTS}

This study has been supported by grants from Astellas, Finnish Cancer Society, Academy of Finland (Grant 132385 and 260931) and the Competitive State Research Financing of Tampere University Hospital (Grant No. 9P053). TV has received a lecture fee from Abbvie and GSK, travel support from Ferring, Sanofi and Astellas and nonrestricted grants from Astellas and Amgen. TJM has received lecture fee from Novartis, has participated in scientific congresses at the expense of Ferring Pharmaceuticals and Astellas and has received nonrestricted research prize from Astellas. TLJT has served as a board member for Astellas, Amgen and Pfizerand, and has received consulting fees from Orion Pharma, lecture fees from Astellas and Amgen, payment for developing educational presentations from GlaxoSmithKline and travel support from Amgen. KT has received lecture fees from GlaxoSmithKline, honoraria for planning national meetings for GlaxoSmithKline, Astellas and travel support from Astellas, Ipsen, Janssen-Cilag. He has received a nonrestricted grant from Amgen, is a payed consultant/member of advisory board for Astellas, GlaxoSmithKline, Amgen, Pfizer, Sanofi, Janssen-Cilag and has affiliation/ employment for Medivation. U-HS holds a patent for the assay of free PSA and has received royalties from the patent. Funding sources have not affected the acquisition, analysis or interpretation of data, or any other aspect of scientific purity.

\section{REFERENCES}

Bosetti C, Rosato V, Gallus S, La Vecchia C (2012) Aspirin and urologic cancer risk: an update. Nat Rev Urol 9(2): 102-110.

Brasky TM, Velicer CM, Kristal AR, Peters U, Potter JD, White E (2010) Nonsteroidal anti-inflammatory drugs and prostate cancer risk in the VITaminsAnd Lifestyle (VITAL) cohort. Cancer Epidemiol Biomarkers Prev 19(12): 3185-3188.

Cho E, Curhan G, Hankinson SE, Kantoff P, Atkins MB, Stampfer M, Choueiri TK (2011) Prospective evaluation of analgesic use and risk of renal cell cancer. Arch Intern Med 171(16): 1487-1493.

Crawford ED (2009) Understanding the epidemiology, natural history, and key pathways involved in prostate cancer. Urology 73(5 Suppl): S4-S10.

Corley DA, Kerlikowske K, Verma R, Buffler P (2003) Protective association of aspirin/NSAIDs and esophageal cancer: a systematic review and meta-analysis. Gastroenterology 124(1): 47-56.

Coussens L, Werb Z (2002) Inflammation and cancer. Nature 420(6917): $860-867$.

Cryer B, Feldman M (1998) Cyclooxygenase-1 and cyclooxygenase-2 selectivity of widely used nonsteroidal anti-inflammatory drugs. Am J Med 104: 413-421.

Cuzick J, Otto F, Baron JA, Brown PH, Burn J, Greenwald P, Jankowski J, La Vecchia C, Meyskens F, Senn HJ, Thun M (2009) Aspirin and nonsteroidal anti-inflammatory drugs for cancer prevention: an international consensus statement. Lancet Oncol 10(5): 501-507.

Daugherty SE, Pfeiffer RM, Sigurdson AJ, Hayes RB, Leitzmann M, Schatzkin A, Hollenbeck AR, Silverman DT (2011) Nonsteroidal antiinflammatory drugs and bladder cancer: a pooled analysis. Am J Epidemiol 173(7): 721-730.

de Koning HJ, Auvinen A, Berenguer Sanchez A, Calais da Silva F, Ciatto S, Denis L, Gohagan JK, Hakama M, Hugosson J, Kranse R, Nelen V, Prorok PC, Schröder FH. European Randomized Screening for Prostate Cancer (ERSPC) TrialInternational Prostate Cancer Screening Trials Evaluation Group (2002) Large-scale randomized prostate cancer screening trials: program performances in the European Randomized Screening for Prostate Cancer trial and the Prostate, Lung, Colorectal and Ovary cancer trial. Int J Cancer 97(2): 237-244.

De Marzo AM, Platz EA, Sutcliffe S, Xu J, Grönberg H, Drake CG, Nakai Y, Isaacs WB, Nelson WG (2007) Inflammation in prostate carcinogenesis. Nat. Rev. Cancer 7: 256-269.

De Nunzio C, Kramer G, Marberger M, Montironi R, Nelson W, Schröder F, Sciarra A, Tubaro A (2011) The controversial relationship between benign prostatic hyperplasia and prostate cancer: the role of inflammation. Eur Urol 60(1): 106-117.

Ferlay J., Parkin DM, Steliarova-Foucher E (2010) Estimates of cancer incidence and mortality in Europe in 2008. Eur J Cancer 46(4): 765-781.

Gupta S, Srivastava M, Ahmad N, Bostwick DG, Mukhtar H (2000) Over-expression of cyclooxygenase-2 in human prostate adenocarcinoma. Prostate 42(1): 73-78.

Gurpinar E, Grizzle WE, Piazza GA (2014) NSAIDs inhibit tumorigenesis, but how? Clin Cancer Res 20(5): 1104-1113.

Hirano T (1992) The biology of interleukin-6. Chem Immunol 51: 153-180. 
Hobisch A, Rogatsch H, Hittmair A, Fuchs D, Bartsch Jr G, Klocker H, Bartsch G, Culig Z (2000) Immunohistochemical localization of interleukin- 6 and its receptor in benign, premalignant and malignant prostate tissue. J. Pathol 191: 239-244.

Hussain T, Gupta S, Mukhtar H (2003) Cyclooxygenase-2 and prostate carcinogenesis. Cancer Lett 191(2): 125-135.

Khuder SA, Mutgi AB (2001) Breast cancer and NSAID use: a meta-analysis. Br J Cancer 84: 1188-1192.

Kilpeläinen TP, Tammela TL, Malila N, Hakama M, Santti H, Määttänen L, Stenman UH, Kujala P, Auvinen A (2013) Prostate cancer mortality in the Finnish randomized screening trial. J Natl Cancer Inst 105(10): 719-725.

Kulkarni SK, Jain NK, Singh A (2000) Cyclooxygenase isoenzymes and newer therapeutic potential for selective COX-2 inhibitors. Methods Find Exp Clin Pharmacol 22(5): 291-298.

Langman MJ, Cheng KK, Gilman EA, Lancashire RJ (2000) Effect of anti-inflammatory drugs on overall risk of common cancer: case-control study in general practice research database. BMJ 320(7250): 1642-1646.

Leitzmann MF, Stampfer MJ, Ma J, Chan JM, Colditz GA, Willett WC, Giovannucci E (2002) Aspirin use in relation to risk of prostate cancer. Cancer Epidemiol Biomarkers Prev 11(10 Pt 1): 1108-1111.

MacLennan GT, Eisenberg R, Fleshman RL, Taylor JM, Fu P, Resnick MI, Gupta S (2006) The influence of chronic inflammation in prostatic carcinogenesis: a 5-year followup study. J Urol 176(3): 1012-1016.

Mahmud SM, Franco EL, Aprikian AG (2010) Use of nonsteroidal antiinflammatory drugs and prostate cancer risk: a meta-analysis. Int J Cancer 127(7): 1680-1691.

Martikainen J, Rajaniemi S (2002) Drug reimbursement systems in EU member states, Iceland and Norway. The Social Insurance Institution, Finland, Social security and health reports 54: Helsinki, Finland. http://www.kela.fi/ in/internet/english.nsf/NET/100203115310PN.

Murad AS, Down L, Davey Smith G, Donovan JL, Athene Lane J, Hamdy FC, Neal DE, Martin RM (2011) Associations of aspirin, non-steroidal anti-inflammatory drug and acetaminophen use with PSA-detected prostate cancer: findings from a large, population-based, case-control study (the ProtecT study). Int J Cancer 128(6): 1442-1448.

Patel A, Klein E (2009) Risk factors for prostate cancer. Nat Clin Pract Urol 6 : 87-95.

Richardsen E, Uglehus RD, Due J, Busch C, Busund LT (2010) COX-2 is overexpressed in primary prostate cancer with metastatic potential and may predict survival. A comparison study between COX-2, TGF-beta, IL-10 and Ki67. Cancer Epidemiol 34(3): 316-322.

Rosenbaum PR, Rubin DB (1984) Reducing bias in observational studies using subclassification on the propensity score. J Am Stat Assoc 79: 516-524.

Ross JA, Blair CK, Cerhan JR, Soler JT, Soler JT, Hirsch BA, Roesler MA, Higgins RR, Nguyen PL (2011) Nonsteroidal anti-inflammatory drug and acetaminophen use and risk of adult myeloid leukemia. CancerEpidemiol Biomarkers Prev 20(8): 1741-1750.

Rostom A, Dubé C, Lewin G, Tsertsvadze A, Barrowman N, Code C, Sampson M, Moher D. U.S. Preventive Services Task Force (2007) Nonsteroidal anti-inflammatory drugs and cyclooxygenase-2 inhibitors for primary prevention of colorectal cancer: a systematic review prepared for the U.S. Preventive Services Task Force. Ann Intern Med 146(5): 376-389.

Sfanos KS, De Marzo AM (2012) Prostate cancer and inflammation: the evidence. Histopathology 60(1): 199-215.

Shao N, Feng N, Wang Y, Mi Y, Li T, Hua L (2012) Systematic review and meta-analysis of COX-2 expression and polymorphisms in prostate cancer. Mol Biol Rep 39(12): 10997-11004.

Siegel R, Ward E, Brawley O, Jemal A (2011) Cancer statistics, 2011: the impact of eliminating socioeconomic and racial disparities on premature cancer deaths. CA Cancer J Clin 61(4): 212-236.
Smith PC, Hobisch A, Lin D-L, Culig Z, Keller ET (2001) Interleukin-6 and prostate cancer progression. Cytokine Growth Factor Rev 12: 33-40.

Statistics Finland. Finland in figures: Population structure [online] available athttp://www.stat.fi/til/vaerak/index.html[30 July 2011].

Steinberg GD, Carter BS, Beaty TH, Childs B, Walsh PC (1990) Family history and the risk of prostate cancer. Prostate 17(4): 337-347.

Stenman UH (2011) SPINK1: a new therapeutic target in cancer? Clin Chem 57(11): 1474-1475.

Sørensen HT, Friis S, Nørgård B, Mellemkjaer L, Blot WJ, McLaughlin JK, Ekbom A, Baron JA (2003) Risk of cancer in a large cohort of nonaspirin NSAID users: a population-based study. Br J Cancer 88: 1687-1692.

Tian W, Zhao Y, Liu S, Li X (2010) Meta-analysis on the relationship between nonsteroidal anti-inflammatory drug use and gastric cancer. Eur J Cancer Prev 19(4): 288-298.

Teppo L, Pukkala E, Lehtonen M (1994) Data quality and quality control of a population-based cancer registry. Acta Oncol 33(4): 365-369.

The European Stroke Association (ESO) Executive Committee and the ESO Writing Committee (2008) Guidelines for management of ischaemic stroke and transient ischaemic attack 2008. Cerebrovasc Dis 25: 457-507.

Tomlins SA, Rhodes DR, Yu J, Mehra R, Perner S, Demichelis F, Helgeson BE, Laxman B, Morris DS, Cao Q, Cao X, Andrén O, Fall K, Johnson L, Wei JT, Shah RB, Al-Ahmadie H, Eastham JA, Eggener SE, Fine SW, Hotakainen K, Stenman UH, Tsodikov A, Gerald WL, Lilja H, Reuter VE, Kantoff PW, Scardino PT, Rubin MA, Bjartell AS, Chinnaiyan AM (2008) The role of SPINK1 in ETS rearrangement-negative prostate cancers. Cancer Cell 13(6): 519-528.

Turesson C, Matteson EL (2013) Malignancy as a comorbidity in rheumatic diseases. Rheumatology 52(1): 5-14.

Twillie DA, Eisenberger MA, Carducci MA, Hseih WS, Kim WY, Simons JW (1995) Interleukin-6: a candidate mediator of human prostate cancer morbidity. Urology 45: 542-549.

Veitonmäki T, Tammela TL, Auvinen A, Murtola T (2013) Use of aspirin, but not other non-steroidal anti-inflammatory drugs is associated with decreased prostate cancer risk at the population level. Eur J Cancer 49(4): 938-945.

Vinogradova Y, Coupland C, Hippisley-Cox J (2011) Exposure to cyclooxygenase- 2 inhibitors and risk of cancer: nested case-control studies. Br J Cancer 105(3): 452-459.

Wagenlehner FM, Elkahwaji JE, Algaba F, Bjerklund-Johansen T, Naber KG, Hartung R, Weidner W (2007) The role of inflammation and infection in the pathogenesis of prostate carcinoma. BJU Int 100(4): 733-737.

Walter RB, Milano F, Brasky TM, White E (2011) Long-term use of acetaminophen, aspirin, and other nonsteroidal anti-inflammatory drugs and risk of hematologic malignancies: results from the prospective Vitamins and Lifestyle (VITAL) study. J Clin Oncol 29(17): 2424-2431.

Wang X, Baek SJ, Eling TE (2013) The diverse roles of nonsteroidal anti-inflammatory drug activated gene (NAG-1/GDF15) in cancer. Biochem Pharmacol 85(5): 597-606.

World Health Organization. ATC/DDD index database [online] available at http://www.whocc.no/ddd/definition_and_general_considera/ [30 July 2011].

Yoshimura R, Sano H, Masuda C, Kawamura M, Tsubouchi Y, Chargui J, Yoshimura N, Hla T, Wada S (2000) Expression of cyclooxygenase-2 in prostate carcinoma. Cancer 89(3): 589-596.

This work is published under the standard license to publish agreement. After 12 months the work will become freely available and the license terms will switch to a Creative Commons AttributionNonCommercial-Share Alike 3.0 Unported License.

Supplementary Information accompanies this paper on British Journal of Cancer website (http://www.nature.com/bjc) 